\title{
Variability of post-exercise pulmonary capillary wedge pressure recovery. Implications for noninvasive echocardiographic diagnostics
}

\author{
Jaroslav Meluzinn ${ }^{\mathrm{a}, b \#}$, Petr Hude ${ }^{\mathrm{a}, \mathrm{b} \#,}$, Jan Krejci ${ }^{\mathrm{a}, \mathrm{b}}$, Lenka Spinarova ${ }^{\mathrm{a}, \mathrm{b}}$, Pavel Leinveber ${ }^{\mathrm{a}}$, Radka Stepanovac, Petr Nemec ${ }^{\mathrm{d}}$
}

\begin{abstract}
Aim. The aim of our study was to assess the course of immediate post-exercise pulmonary capillary wedge pressure (PCWP) changes to identify the optimal time window for the noninvasive diagnostics of exercise-induced PCWP elevation.

Methods and Results. Seventy-one patients at risk of heart failure with normal left ventricular ejection fraction underwent simultaneous exercise echocardiography and right heart catheterization. The ratio of early left ventricular filling velocity (E) to early diastolic mitral annular velocity ( $\left.e^{\prime}\right)$ was used to predict noninvasively exercise-induced PCWP elevation. Fifty-one patients had exercise-induced PCWP elevation $\geq 8 \mathrm{mmHg}$ and reached peak exercise PCWP $\geq 20$ $\mathrm{mmHg}$. Rapid post-exercise recovery of PCWP within 2 min was achieved in $18(35.3 \%)$ patients. Intermediate postexercise PCWP recovery at 3 and 4 min was found in 16 (31.4\%) patients while late post-exercise PCWP recovery ( $\geq 5$ min) was achieved in 17 (33.3\%) patients.

Conclusion. The course of post-exercise PCWP recovery is highly variable, and a significant proportion of patients have only a brief period ( $\leq 2 \mathrm{~min}$ ) of exercise-induced PCWP elevation. This fact should be taken into account in noninvasive assessment of exercise-induced PCWP.
\end{abstract}

Key words: pulmonary capillary wedge pressure, exercise, wedge pressure recovery

Received: September 19, 2012; Accepted with revision: February 27, 2013; Available online: March 22, 2013 http://dx.doi.org/10.5507/bp.2013.016

${ }^{a}$ Department of Cardiovascular Diseases, ICRC, St. Anne's University Hospital in Brno, Czech Republic ${ }^{b}$ Department of Cardiovascular Diseases, Masaryk University, Brno

'ICRC, St. Anne's University Hospital in Brno, Brno

${ }^{d}$ Centre of Cardiovascular and Transplant Surgery, ICRC, St. Anne's University Hospital in Brno

Corresponding author: Jaroslav Meluzin, e-mail: jaroslav.meluzin@fnusa.cz

"The authors contributed equally to the work

\section{INTRODUCTION}

Pulmonary capillary wedge pressure (PCWP) is commonly used as a surrogate measure for left ventricular filling pressure (LVFP) and represents one of the basic parameters for the diagnostics of heart failure with normal left ventricular ejection fraction ${ }^{1}$ (HFNEF). The current European Society of Cardiology (ESC) guidelines for the diagnostics of HFNEF ( ref. $^{1}$ ) rely on only measures made at rest. However, a significant proportion of patients with unexplained exertional dyspnea or fatigue and normal LV ejection fraction (EF) have been found to manifest elevated LVFP only during exercise ${ }^{2,3}$. Thus, exercise echocardiography, utilizing mainly the exercise-induced elevation in the ratio of peak early diastolic transmitral flow velocity (E) to peak early diastolic mitral annular velocity (e') has been used to detect noninvasively exercise LVFP elevation ${ }^{2,4}$. However, it is difficult to obtain good quality echocardiographic images during exercise and at peak exercise. The quality and interpretability of exercise images are limited by tachycardia, by heavy breathing and the impossibility of obtaining images while the breath is held, etc. Thus, the early post-exercise period is usually utilized to obtain the necessary images including Doppler transmitral LV filling flow and pulsed-wave Doppler tissue velocities at the septal and lateral mitral annular corners.
However, in current clinical practice, little emphasis is given to the acquisition of Doppler images immediately after the end of exercise. Instead, the recommendations of the European Association of Echocardiography (EAE) and the American Society of Echocardiography (ASE) support the acquisition of images for $\mathrm{E}$ and $\mathrm{e}^{\prime}$ evaluation after post-exercise 2-D images have been obtained for wall motion analysis ${ }^{5}$. We hypothesize that in patients with a rapid PCWP post-exercise recovery, a 1-2 min delay may result in the acquisition of Doppler data at the time of PCWP normalization or close to its normalization. Such Doppler data and the indices derived from them are unlikely to reflect the exercise-induced PCWP elevation. Therefore, the aim of our study was to assess the course of immediate post-exercise PCWP changes to identify the optimal time window for the noninvasive diagnostics of exercise-induced PCWP elevation.

\section{MATERIALS AND METHODS}

\section{Patient population}

Our study included patients after orthotopic heart transplantation who underwent simultaneous exercise echocardiography and exercise right heart catheterization. The inclusion criteria of this study were: i. sinus 
rhythm on electrocardiogram; ii. $\geq 6$ months after the heart transplantation; iii. no history of myocardial infarction or angina pectoris after the heart transplantation; and iv. an initial transthoracic echocardiography of acceptable quality demonstrating normal LV EF ( $\geq 50 \%$ ), no significant pericardial effusion, and no mitral regurgitation other than trivial. All patients who fulfilled the inclusion criteria entered and finished the study protocol. The study was in compliance with the Declaration of Helsinki and was approved by the ethics committee at St. Anne's Hospital. All patients gave their informed consent to the investigations.

\section{Study protocol}

The study was performed during a 2- to 3-day hospitalization. On the first day, conventional echocardiography was performed to determine whether the patients met the echocardiographic inclusion criteria. On the following day, resting, exercise, and recovery echocardiography and right heart catheterization with PCWP measurement were performed simultaneously. Resting pre-exercise measurements were initially performed with the patient's trunk and legs in a horizontal position (supine) and then with the legs slightly elevated in order to prepare for cycling. Subsequently, a graded supine cycle ergometry exercise, limited by the onset of symptoms, was performed starting at $25 \mathrm{~W}$ for $2 \mathrm{~min}$. The load was then increased in increments of $25 \mathrm{~W}$ at 2-min intervals until the occurrence of the first symptom (dyspnea or fatigue). All exercise tests were performed on an Ergoline ergometer $\mathrm{GmbH}$ (ER900L, Bitz, Germany). During the exercise, wall motion and LV filling were monitored in the apical 4-chamber view and the PCWP was monitored continually. PCWP, blood pressure, and heart rate recordings and measures were obtained at rest both in the supine position and with legs elevated, at the end of each 2-min exercise interval, at peak exercise, and at every $1 \mathrm{~min}$ of post-exercise recovery. The post-exercise recovery measurements were terminated at the time of PCWP normalization, defined as the achievement of resting leg elevation PCWP value \pm $2 \mathrm{mmHg}$. Complete 2-D and tissue Doppler echocardiography, as well as pulsed-wave Doppler recordings of aortic and transmitral flows, were obtained in patients at rest in the horizontal position and with leg elevation. Moreover, 2-D apical 4-chamber views, pulsed-Doppler recordings of transmitral flow, and tissue Doppler imaging of the septal and lateral mitral annular motion were acquired within 60-90 s after the end of exercise and at the time of post-exercise PCWP normalization.

\section{Right heart catheterization}

A 7F Swan-Ganz thermodilution catheter (model 131HF7, Baxter Healthcare Corporation, Irvine, CA, USA) was advanced via the right jugular vein into the pulmonary capillary wedge position. The optimal balloon position was verified by the presence of characteristic wedge pressure waveforms. PCWP was measured with the zero level at the midaxillary line. After obtaining the balloon wedge position, the resting pre-exercise catheterization echocardiography was started with patients in a horizontal position. At the time of transmitral Doppler flow recording, the PCWP, heart rate, and systemic blood pressure measurements were obtained using a multiparametric modul Ultraview SL (TM) 91496 (Spacelabs Healthcare, Issaquah, WA, USA). PCWP was averaged over pressure waveform data obtained during a 12-s interval and expressed as a mean. Measurements of PCWP, heart rate, and blood pressure were repeated at rest 5 min after patient leg elevation and during the exercise at the end of each workload, at the time of termination of exercise (peak exercise), and at the end of each min of the post-exercise recovery period until the PCWP normalization. On the day of catheterization, the morning medication was omitted.

\section{Echocardiography}

Echocardiographic examinations were performed using Vivid E9 (GE Healthcare, Wauwatosa, WI, USA) with a M5S transducer. At rest, both in the supine position and with leg elevation, grey-scale 2-D images were recorded from the parasternal short axis views at the base, at the level of papillary muscles, and at the apex, as well as from the apical 2-, 3-, and 4- chamber views. Transmitral flows were recorded using pulsed-wave Doppler echocardiography. Pulsed-wave Doppler tissue imaging (DTI) of mitral annular motion was performed in the apical 4-chamber view. A sample volume of $6.0 \mathrm{~mm}$ was placed on septal and lateral mitral annular corners. A narrow angle sector was used to obtain Doppler tissue images at the high frame rates above 150 frames/s. All Doppler recordings were done during shallow respiration or end-expiratory apnea and were digitally stored for the subsequent off-line computer analysis using EchoPAC PC versions 108.1.5110.1.1 (GE Vingmed Ultrasound A/S, Horten, Norway).

Echocardiographic measurements were performed according to the recommendations of the ASE (ref. ${ }^{6}$ ). LV mass was estimated using the Devereux formula ${ }^{7}$. LV and left atrial volumes were calculated with the biplane method of disks ${ }^{6}$ using apical 4- and 2-chamber views. E velocity was acquired from conventional pulsed-wave Doppler recordings. To obtain Doppler tissue e' velocity, the values measured at the septal and lateral corners were averaged. All echocardiographic parameters were obtained as a mean of 3-6 consecutive heart cycles. Echocardiographic analyses were performed by one experienced observer (JM), who was unaware of the PCWP values. The reproducibility of the transmitral pulsed Doppler and DTI velocities of this reader have already been published ${ }^{8,9}$, variabilities of $E$ and $\mathrm{e}^{\prime}$ velocities were below $5 \%$.

\section{Statistical analysis}

The data are presented as means \pm standard error of the mean (SEM) or number (\%) of subjects. Because the assumption of normal distribution was not remarkably violated (Shapiro-Wilk test), a one-way ANOVA model was applied to compare the individual groups for continuous variables and a standard t-test was used for mutual comparison of Groups A, B, and C. A chi-squared test was applied to compare the groups in categorical variables. Univariate and multivariate logistic regression models 
were used to analyze the potential association of clinical and echocardiographic parameters with the early postexercise PCWP recovery. For the parameters with potential predictive power (providing at least $P<0.1$ in univariate logistic regression), various multivariate models were used to explore the independent predictors. The significance of regression coefficients was tested using the Wald statistic. Results with $P$ value $<0.05$ were considered statistically significant.

\section{RESULTS}

Seventy-one patients who fulfilled the inclusion criteria underwent the complete exercise study protocol. The course of post-exercise PCWP recovery was analyzed in the 51 subjects with a significant $(\geq 8 \mathrm{mmHg}$ ) exerciseinduced PCWP elevation reaching peak exercise PCWP $\geq 20 \mathrm{mmHg}$. The patients were divided into 3 groups according to the time interval from peak exercise to the moment of post-exercise PCWP normalization. Group A comprised 18 patients with early post-exercise PCWP recovery ( $\leq 2$ post-exercise min). Group B consisted of 16 subjects with the intermediate post-exercise PCWP recovery (normalization at 3 or 4 min after the end of exer- cise). Group $\mathrm{C}$ included 17 patients with late post-exercise PCWP recovery ( $\geq 5 \mathrm{~min}$ after the end of exercise). The baseline clinical characteristics of the whole cohort of patients and of the individual groups are shown in Table 1.

Table 2 summarizes the hemodynamic and echocardiographic Doppler data related to the noninvasive prediction of PCWP for the whole cohort of patients and separately in Groups A, B, and C. As compared to the remaining groups, patients with early post-exercise PCWP recovery (Group A) had higher resting and exercise heart rates and higher values of exercise systolic blood pressure. Multivariate regression analysis suggested the association of beta blocker administration and resting heart rate with early post-exercise PCWP recovery. Beta blocker administration suggested lower odds of early PCWP recovery $(P=0.008, \mathrm{OR}=0.07,95 \% \mathrm{CI}: 0.01-0.50)$, and a higher resting heart rate suggested higher odds $(P=0.002, \mathrm{OR}=1.18$, 95\% CI: 1.06-1.31). However, the clinical meaning of these findings should be confirmed in a larger patient population. At the time of post-exercise PCWP recovery, E/e' and $\mathrm{E}$ post-exercise recoveries were achieved in 21 and 15 patients, respectively.

Table 3 shows the time to post-exercise PCWP normalization in individual subjects. A significant proportion of patients (18 out of $51 ; 35.3 \%$ ) exhibited early post-exercise

Table 1. Baseline clinical and echocardiographic data of all patients and those grouped according to post-exercise pulmonary capillary wedge pressure recovery.

\begin{tabular}{|c|c|c|c|c|c|}
\hline & $\begin{array}{l}\text { All patients } \\
\quad(\mathrm{n}=51)\end{array}$ & $\begin{array}{l}\text { Group A } \\
(\mathrm{n}=18)\end{array}$ & $\begin{array}{l}\text { Group B } \\
(\mathrm{n}=16)\end{array}$ & $\begin{array}{l}\text { Group C } \\
(\mathrm{n}=17)\end{array}$ & $P$ \\
\hline \multicolumn{6}{|l|}{ Clinical characteristics } \\
\hline Age (years) & $55.4(1.51)$ & $54.4(3.16)$ & $54.5(1.80)$ & $57.2(2.64)$ & 0.691 \\
\hline Men (\%) & $47(92.2 \%)$ & $16(88.9 \%)$ & $14(87.5 \%)$ & $17(100 \%)$ & 0.334 \\
\hline Time since OHT (months) & $54.1(7.58)$ & $54.1(13.06)$ & $63.1(14.47)$ & $45.8(12.37)$ & 0.663 \\
\hline Hypertension (\%) & $43(84.3 \%)$ & $16(88.9 \%)$ & $13(81.3 \%)$ & $14(82.4 \%)$ & 0.799 \\
\hline Hyperlipidemia (\%) & $50(98.0 \%)$ & $17(94.4 \%)$ & $16(100 \%)$ & $17(100 \%)$ & 0.393 \\
\hline Diabetes mellitus (\%) & $28(54.9 \%)$ & $9(50.0 \%)$ & $7(43.8 \%)$ & $12(70.6 \%)$ & 0.263 \\
\hline Body mass index $\left(\mathrm{kg} / \mathrm{m}^{2}\right)$ & $28.2(0.38)$ & $28.2(0.52)$ & $29.8(0.62)^{\dagger \dagger}$ & $26.6(0.65)$ & 0.003 \\
\hline Exercise duration (s) & $334.5(8.80)$ & $317.1(18.85)$ & $354.8(13.02)$ & $333.8(11.53)$ & 0.221 \\
\hline \multicolumn{6}{|l|}{ Medication } \\
\hline $\begin{array}{l}\text { ACEi or AT II receptor } \\
\text { blocker }(\%)\end{array}$ & $36(70.6 \%)$ & $12(66.7 \%)$ & $12(75.0 \%)$ & $12(70.6 \%)$ & 0.868 \\
\hline Beta blocker $(\%)$ & $40(78.4 \%)$ & $10(55.6 \%)^{\dagger}$ & $14(87.5 \%)$ & $16(94.1 \%)$ & 0.012 \\
\hline Diuretic (\%) & $21(41.2 \%)$ & $4(22.2 \%)$ & $9(56.3 \%)$ & $8(47.1 \%)$ & 0.110 \\
\hline Calcium antagonist (\%) & $21(41.2 \%)$ & $11(61.1 \%)^{\dagger}$ & $7(43.8 \%)$ & $3(17.6 \%)$ & 0.032 \\
\hline Statin $(\%)$ & $47(92.2 \%)$ & $18(100 \%)$ & $14(87.5 \%)$ & $15(88.2 \%)$ & 0.305 \\
\hline \multicolumn{6}{|l|}{ 2-D echocardiography } \\
\hline $\operatorname{EDVI}\left(\mathrm{mL} / \mathrm{m}^{2}\right)$ & $42.4(1.19)$ & $41.9(1.85)$ & $43.9(2.00)$ & $41.5(2.38)$ & 0.708 \\
\hline $\operatorname{ESVI}\left(\mathrm{mL} / \mathrm{m}^{2}\right)$ & $14.5(0.48)$ & $13.7(0.64)$ & $15.0(0.76)$ & $14.9(1.07)$ & 0.444 \\
\hline LV EF (\%) & $65.8(0.76)$ & $67.0(1.14)$ & $66.0(1.24)$ & $64.3(1.52)$ & 0.336 \\
\hline $\operatorname{LVMI}\left(\mathrm{g} / \mathrm{m}^{2}\right)$ & $99.9(3.02)$ & $103.3(6.15)$ & $96.8(5.24)$ & $99.4(4.20)$ & 0.683 \\
\hline LAVI $\left(\mathrm{mL} / \mathrm{m}^{2}\right)$ & $43.4(1.58)$ & $41.9(1.86)$ & $44.8(2.89)$ & $43.8(3.44)$ & 0.759 \\
\hline RWT (mm) & $0.54(0.01)$ & $0.58(0.02)$ & $0.50(0.03)$ & $0.53(0.02)$ & 0.144 \\
\hline
\end{tabular}

ACEi, angiotensin-converting enzyme inhibitor; AT, angiotensin; EDVI, end-diastolic volume index; ESVI, end-systolic volume index; LAVI, left atrial volume index; LV EF, left ventricular ejection fraction; LVMI, left ventricular mass index; OTH, orthotopic heart transplantation; RWT, relative wall thickness.

Data is presented as mean $\pm \mathrm{SEM}$ or number (\%). $P$, statistical test comparing all 3 groups A, B, and C. $\dagger P<0.05$ vs Group C, $\uparrow \dagger P<0.01$ vs Group C. 
Table 2. Doppler, hemodynamic, and pulmonary capillary wedge pressure data of all patients and those grouped according to post-exercise pulmonary capillary wedge pressure recovery.

\begin{tabular}{|c|c|c|c|c|c|}
\hline & $\begin{array}{l}\text { All patients } \\
\quad(\mathrm{n}=51)\end{array}$ & $\begin{array}{l}\text { Group A } \\
(\mathrm{n}=18)\end{array}$ & $\begin{array}{l}\text { Group B } \\
(\mathrm{n}=16)\end{array}$ & $\begin{array}{l}\text { Group C } \\
(\mathrm{n}=17)\end{array}$ & $P$ \\
\hline \multicolumn{6}{|l|}{ Rest (supine position) } \\
\hline Heart rate (beats/min) & $75.8(1.27)$ & $81.8(1.67)^{* * \dagger \dagger}$ & $72.6(2.25)$ & $72.6(1.98)$ & 0.001 \\
\hline Systolic BP (mmHg) & $139.9(2.24)$ & $141.1(2.23)$ & $134.9(4.45)$ & $143.3(4.66)$ & 0.307 \\
\hline $\mathrm{E}(\mathrm{cm} / \mathrm{s})$ & $76.1(2.96)$ & $76.1(4.27)$ & $79.7(6.29)$ & $72.8(4.81)$ & 0.645 \\
\hline $\mathrm{e}^{\prime}(\mathrm{cm} / \mathrm{s})$ & $10.7(0.28)$ & $10.1(0.51)^{*}$ & $11.4(0.38)$ & $10.6(0.52)$ & 0.151 \\
\hline $\mathrm{E} / \mathrm{e}^{\prime}$ & $7.3(0.34)$ & $7.7(0.51)$ & $7.1(0.64)$ & $7.1(0.63)$ & 0.694 \\
\hline PCWP (mmHg) & $11.9(0.57)$ & $11.8(1.26)$ & $12.4(0.92)$ & $11.6(0.69)$ & 0.851 \\
\hline \multicolumn{6}{|l|}{ Rest (leg elevation) } \\
\hline Heart rate (beats/min) & $75.6(1.24)$ & $81.6(1.61)^{* * \dagger \dagger}$ & $72.4(2.12)$ & $72.3(1.98)$ & 0.001 \\
\hline Systolic BP (mmHg) & $144.4(2.28)$ & $146.9(2.95)$ & $139.9(4.14)$ & $146.1(4.70)$ & 0.409 \\
\hline $\mathrm{E}(\mathrm{cm} / \mathrm{s})$ & $89.7(2.85)$ & $90.1(5.47)$ & $95.0(5.05)$ & $84.4(4.31)$ & 0.312 \\
\hline $\mathrm{e}^{\prime}(\mathrm{cm} / \mathrm{s})$ & $11.6(0.31)$ & $11.2(0.65)$ & $12.2(0.35)$ & $11.3(0.57)$ & 0.381 \\
\hline $\mathrm{E} / \mathrm{e}^{\prime}$ & $8.1(0.36)$ & $8.4(0.73)$ & $7.9(0.50)$ & $7.9(0.66)$ & 0.821 \\
\hline PCWP (mmHg) & $15.5(0.59)$ & $15.2(1.05)$ & $16.5(1.24)$ & $14.8(0.72)$ & 0.496 \\
\hline \multicolumn{6}{|l|}{ Peak exercise } \\
\hline Heart rate (beats/min) & $104.1(1.72)$ & $113.0(2.46)^{* *+\dagger}$ & $103.7(2.25)^{\dagger}$ & $95.0(2.44)$ & $<0.001$ \\
\hline Systolic BP (mmHg) & $157.6(2.51)$ & $166.3(3.08)^{* \dagger}$ & $156.3(3.67)$ & $150.1(5.21)$ & 0.024 \\
\hline $\mathrm{E}(\mathrm{cm} / \mathrm{s})$ & $122.4(2.68)$ & $116.7(4.33)$ & $126.7(4.70)$ & $123.1(4.69)$ & 0.335 \\
\hline $\mathrm{e}^{\prime}(\mathrm{cm} / \mathrm{s})$ & $13.7(0.39)$ & $13.1(0.80)$ & $14.6(0.42)$ & $13.4(0.78)$ & 0.262 \\
\hline $\mathrm{E} / \mathrm{e}^{\prime}$ & $9.2(0.32)$ & $9.2(0.49)$ & $8.7(0.41)$ & $9.7(0.70)$ & 0.475 \\
\hline PCWP (mmHg) & $29.5(0.65)$ & $28.5(1.15)$ & $31.0(1.41)$ & $29.3(0.71)$ & 0.285 \\
\hline \multicolumn{6}{|l|}{ Post-exercise recovery } \\
\hline Heart rate (beats/min) & $88.8(1.98)$ & $102.1(2.65)^{* *+\dagger}$ & $83.6(2.36)$ & $79.6(2.37)$ & $<0.001$ \\
\hline Systolic BP (mmHg) & $154.0(2.80)$ & $162.6(3.61)^{*}$ & $147.8(5.36)$ & $151.1(4.97)$ & 0.074 \\
\hline $\mathrm{E}(\mathrm{cm} / \mathrm{s})$ & $93.4(2.78)$ & $90.7(4.29)$ & $96.1(5.74)$ & $92.9(4.43)$ & 0.748 \\
\hline $\mathrm{e}^{\prime}(\mathrm{cm} / \mathrm{s})$ & $12.3(0.35)$ & $11.7(0.65)$ & $13.2(0.41)$ & $11.9(0.72)$ & 0.169 \\
\hline $\mathrm{E} / \mathrm{e}^{\prime}$ & $7.7(0.38)$ & $8.0(0.53)$ & $7.3(0.49)$ & $7.8(0.88)$ & 0.738 \\
\hline PCWP $(\mathrm{mmHg})$ & $15.9(0.63)$ & $15.3(1.18)$ & $16.8(1.30)$ & $15.5(0.73)$ & 0.597 \\
\hline
\end{tabular}

E, peak early diastolic transmitral velocity; e', peak early diastolic mitral annular velocity; PCWP, pulmonary capillary wedge pressure. Data is presented as mean \pm SEM or number (\%). $P$, statistical test comparing all 3 groups A, B, and C. * $P<0.05$ vs Group B, ** $P<0.01$ vs Group $\mathrm{B}, \uparrow P<0.05$ vs Group $\mathrm{C}, \dagger \dagger P<0.01$ vs Group C.

Table 3. Time to post-exercise pulmonary capillary wedge pressure recovery in individual patients.

\begin{tabular}{|c|c|c|c|c|c|c|c|}
\hline $\begin{array}{l}\text { Time to PCWP } \\
\text { recovery* (min) }\end{array}$ & 1 & 2 & 3 & 4 & 5 & 6 & 7 \\
\hline No. $(\%)$ of patients** & $7(13.7)$ & $11(21.6)$ & $10(19.6)$ & $6(11.8)$ & $10(19.6)$ & $6(11.8)$ & $1(2)$ \\
\hline
\end{tabular}

No, number; PCWP, pulmonary capillary wedge pressure

* Recovery was defined as the achievement of pre-exercise PCWP values at rest with leg elevation $\pm 2 \mathrm{mmHg}$

** Number (\%) of patients achieving PCWP recovery at that time

PCWP recovery within $2 \mathrm{~min}$. Table 4 demonstrates the course of exercise and post-exercise PCWP changes in individual groups. The exercise at 50W was accomplished in all but 2 patients. The 16 subjects with an intermediate time to PCWP recovery ( 3 and $4 \mathrm{~min}$ ) exhibited a mean PCWP decrease of $5.1 \mathrm{mmHg}$ (35.2\% of the exerciseinduced PCWP increase of $14.5 \mathrm{mmHg}$ ) and $8.2 \mathrm{mmHg}$ (56.6\%), respectively, at 1 and 2 min after the end of exercise.

\section{DISCUSSION}

This study provides some new and clinically important facts. It is the first analysis of the time course of post-exercise PCWP recovery in patients after orthotopic heart transplantation with normal LV EF at high risk for HFNEF. It describes high variability in the timing of post-exercise PCWP recovery, ranging from 1 to $7 \mathrm{~min}$. Thirty-five percent of subjects exhibited early post-exercise PCWP normalization within 2 min. More importantly, $13.7 \%$ of patients were found to have very early post-exercise PCWP recovery within $1 \mathrm{~min}$. 
Table 4. The course of exercise and post-exercise pulmonary capillary wedge pressure changes in Groups A, B, and C.

\begin{tabular}{|c|c|c|c|c|}
\hline & \multicolumn{4}{|c|}{ PCWP (mmHg) } \\
\hline & $\begin{array}{c}\text { Group A } \\
(\mathrm{n}=18)\end{array}$ & $\begin{array}{c}\text { Group B } \\
(\mathrm{n}=16)\end{array}$ & $\begin{array}{l}\text { Group C } \\
(\mathrm{n}=17)\end{array}$ & $P$ \\
\hline \multicolumn{5}{|l|}{ Rest } \\
\hline Supine & $11.8(1.26)$ & $12.4(0.92)$ & $11.6(0.69)$ & 0.851 \\
\hline Leg elevation & $15.2(1.05)$ & $16.5(1.24)$ & $14.8(0.72)$ & 0.496 \\
\hline \multicolumn{5}{|l|}{ Exercise } \\
\hline $25 \mathrm{~W}$ & $23.5(1.26)$ & $22.9(1.46)$ & $23.1(0.90)$ & 0.946 \\
\hline $50 \mathrm{~W}$ & $26.6(1.34)$ & $26.7(1.35)$ & $25.8(0.75)$ & 0.819 \\
\hline peak & $28.5(1.15)$ & $31.0(1.41)$ & $29.3(0.71)$ & 0.285 \\
\hline Recovery (min) & $*$ & $*$ & $*$ & \\
\hline 1 & $19.9(1.29)^{* *+\phi}$ & $25.9(1.61)$ & $26.4(0.80)$ & 0.001 \\
\hline 2 & $14.5(1.39)^{* *+\dagger}$ & $22.8(1.37)$ & $26.3(1.12)$ & $<0.001$ \\
\hline 3 & - & $18.6(1.43)$ & $22.9(1.08)$ & 0.021 \\
\hline 4 & - & $16.3(2.39)$ & $20.1(0.91)$ & 0.081 \\
\hline 5 & - & - & $16.8(0.74)$ & - \\
\hline 6 & - & - & $15.7(1.34)$ & - \\
\hline
\end{tabular}

PCWP, pulmonary capillary wedge pressure.

*PCWP values measured at 1-min intervals after the end of exercise until PCWP normalization (= achieving PCWP values at rest with leg elevation $\pm 2 \mathrm{mmHg}$ ).

Data is presented as mean $\pm \mathrm{SEM}$ or number (\%). $P$, statistical test comparing all 3 groups $\mathrm{A}, \mathrm{B}$, and $\mathrm{C}$. ** $P<0.01$ vs $\mathrm{Group} \mathrm{B}, \dagger \dagger P<0.01$ vs Group C.

Several reports have demonstrated the need for exercise in the diagnostic work-up of patients with exertional dyspnea of unknown etiology or of patients at risk of only isolated exercise-induced diastolic dysfunction or HFNEF $\left(\right.$ ref. $\left.^{2,3,10}\right)$. In such patients, the prevalence of isolated exercise-induced HFNEF can be surprisingly high. Borlaug et al. $^{3}$ analyzed 55 patients with exertional dyspnea, LV EF > 50\%, normal BNP assay, and normal pulmonary artery pressure and PCWP. When the exercise PCWP $\geq 25$ $\mathrm{mmHg}$ was used as an indicator of $\mathrm{HFNEF}, 58 \%$ patients had isolated only exercise-induced HFNEF. Thus, exercise is necessary to diagnose $\mathrm{HFNEF}$ in a significant proportion of patients with unexplained exertional dyspnea or fatigue and normal resting hemodynamics. Doppler echocardiography using the $\mathrm{E} / \mathrm{e}^{\prime}$ ratio is standardly used to identify noninvasively the elevation of LVFP under resting conditions ${ }^{1,11-15}$. However, the ability of the $\mathrm{E} / \mathrm{e}^{\prime}$ ratio to determine exercise-induced LVFP elevation is unclear. While some authors describe the ability of E/e' to predict LVFP elevation during exercise ${ }^{2,4}$, others did not find any relation between exercise-induced changes in $\mathrm{E} / \mathrm{e}^{\prime}$ and PCWP (ref. ${ }^{10,16}$ ). There are several possible reasons for these discrepancies. The cohorts of patients analyzed differed in the main diagnosis and in the presence or absence of myocardial ischemia. However, the differences in the timing of post-exercise Doppler images acquisition may also have played a role.

The clinical application of the E/e' ratio requires recordings of pulsed-wave Doppler transmitral flow and pulsed-wave Doppler tissue mitral annular velocities, optimally at both the septal and lateral corners. The acquisition of these images takes approximately 45-60 s. It is clear that for patients with a rapid post-exercise PCWP recovery, the appropriate image acquisition should start immediately after the end of exercise. However, the EAE/
ASE recommendations for the evaluation of LV diastolic function by echocardiography state that: "In cardiac patients, mitral E velocity increases with exertion and stays increased for a few minutes after the termination of exercise, whereas e' velocity remains reduced at baseline, exercise, and recovery. For this reason, E and e' velocity can be recorded after exercise, after 2-D images have been obtained for wall motion analysis" (ref. ${ }^{5}$ ). Using current echocardiographic practices, the time needed to acquire Doppler images for E and e' measurements may vary from 60 to $240 \mathrm{~s}$ after the end of exercise. According to our results, a significant proportion of patients who have a marked exercise-induced PCWP elevation have normalized or near-normalized PCWP by that time. The postexercise $E$ and $e^{\prime}$ values and their ratio in such patients are unlikely to reflect exercise-induced PCWP.

There are currently only limited data on the course of post-exercise PCWP changes and on the timing of postexercise PCWP recovery. The high frequency of early post-exercise PCWP recovery was highlighted by Borlaug et al. $^{3}$ in 32 patients with exercise-induced HFNEF. In 1 min after the exercise, PCWP returned to baseline preexercise leg up values. However, this study presented averaged PCWP data of a whole patient population and did not analyze differences in the velocity of PCWP recovery in individual patients. Our data, obtained on a larger sample of patients with a normal LV EF and exerciseinduced PCWP elevation $\geq 8 \mathrm{mmHg}$ correspond largely to Borlaug's results. We found early post-exercise PCWP recovery within 1 or $2 \mathrm{~min}$ in $13.7 \%$ or $35.3 \%$ of patients, respectively. As demonstrated in Table 4, even patients with an intermediate post-exercise PCWP recovery time of 3 or 4 min exhibited a marked decrease in PCWP in the early 2 -min post-exercise period. Thus, to ensure that post-exercise E and $\mathrm{e}^{\prime}$ are obtained at the time of real 
exercise-induced PCWP elevation, Doppler images should be acquired optimally within the first post-exercise min.

\section{Study limitations}

We studied a selected group of patients after orthotopic heart transplantation in whom morphological, histological, and structural post-transplant changes in the myocardium are likely to affect the severity and course of exercise and immediate post-exercise PCWP changes. The prevalence of patients with rapid, intermediate, and slow post-exercise PCWP recovery may not correspond to that of patients with diastolic dysfunctions of other etiology. This aside the occurrence of a rapid post-exercise PCWP recovery within $2 \mathrm{~min}$ is a reality which should be reflected in recommendations for the noninvasive determination of exercise-induced PCWP elevation.

\section{CONCLUSIONS}

The course of post-exercise PCWP recovery is highly variable and a significant proportion of patients have only a brief period ( $\leq 2 \mathrm{~min}$ ) of exercise-induced PCWP elevation. This fact should be taken into account when assessing exercise PCWP.

\section{ABBREVIATIONS}

ASE, American Society of Echocardiography; DTI, Doppler tissue imaging; E, Early left ventricular filling velocity; e', Early diastolic mitral annular velocity; EAE, European Association of Echocardiography; EF, Ejection fraction; ESC, European Society of Cardiology; HFNEF, Heart failure with normal ejection fraction; LV, Left ventricular; LVFP, Left ventricular filling pressure; PCWP, Pulmonary capillary wedge pressure.

\section{ACKNOWLEDGEMENT}

We are grateful to Stepanka Kunakova and Lucie Cernoskova for their help with the right heart catheterizations. We would like to thank Anne Johnson for the careful language review of the manuscript. The study was supported in part by the European Regional Development Fund - Project FNUSA-ICRC (No. CZ.1.05/1.1.00/02.0123).

Authorship contributions: JM, PH: manuscript writing; JM, PH, JK, LS, PL, PN: study design; JM, PH, JK, PL: data collection; JM, PH, PL: data analysis; JM, PH, RS: data interpretation; RS: statistical analysis; JK, LS, PL, RS, PN: final approval.

Conflict of interest statement: The authors stated that there are no conflicts of interest regarding the publication of this article.

\section{REFERENCES}

1. Paulus WJ, Tschope C, Sanderson JE, Rusconi C, Flachskampf FA, Rademakers FE, Marino P, Smiseth OA, De Keulenaer G, Leite-Moreira AF, Borbély A, Édes I, Handoko ML, Heymans S, Pezzali N, Pieske B, Dickstein K, Fraser AG, and Brutsaert DL. How to diagnose diastolic heart failure: a consensus statement on the diagnosis of heart failure with normal left ventricular ejection fraction by the Heart Failure and Echocardiography Associations of the European Society of Cardiology. Eur Heart J 2007;28:2539-50.

2. Burgess MI, Jenkins C, Sharman JE, MarwickTH. Diastolic stress echocardiography: hemodynamic validation and clinical significance of estimation of left ventricular filling pressure with exercise. J Am Coll Cardiol 2006;47:1891-900.

3. Borlaug BA, Nishimura RA, Sorajja P, Lam CSP, Redfield MM. Exercise hemodynamics enhance diagnosis of early heart failure with preserved ejection fraction. Circ Heart Fail 2010;3:588-95.

4. Talreja DR, Nishimura RA, Oh JK. Estimation of left ventricular filling pressure with exercise by Doppler echocardiography in patients with normal systolic function: a simultaneous echocardiographiccardiac catheterization study. J Am Soc Echocardiogr 2007;20:477-9.

5. Nagueh SF, Appleton ChP, Gillebert TC, Marino PN, Oh JK, Smiseth OA, Waggoner AD, Flachskampf FA, Pellikka PA, and Evangelisa A. Recommendations for the evaluation of left ventricular diastolic function by echocardiography. Eur J Echocardiogr 2009;10:165-93.

6. Lang RM, Bierig M, Devereux RB, Flachskampf FA, Foster E, Pellikka PA, Picard MH, Roman MJ, Seward J, Shanewise J, Solomon S, Spencer KT, Sutton MSJ, Stewart W. Recommendations for chamber quantification. Eur J Echocardiogr 2006;7:79-108.

7. Devereux RB, Alonso DR, Lutas EM, Gottlieb GJ, Campo E, Sachs I, Reichek N. Echocardiographic assessment of left ventricular hypertrophy: comparison to necropsy findings. Am J Cardiol 1986;57:4508.

8. Meluzin J, Spinarova L, Hude P, Krejci J, Polczkova H, Podrouzkova $H$, Pesl M, Orban M, Dusek L, Korinek J. Left ventricular mechanics in idiopathic dilated cardiomyopathy: systolic-diastolic coupling and torsion. J Am Soc Echocardiogr 2009;22:486-93.

9. Meluzin J, Sitar J, Křístek J, Prosecký R, Pešl M, Podroužková H, Soška V, Panovský R, Dušek L. The role of exercise echocardiography in the diagnostics of heart failure with normal left ventricular ejection fraction. Eur J Echocardiogr 2011;12:591-602.

10. Maeder MT, Thompson BR, Brunner-La Rocca HP, Kaye DM Hemodynamic basis of exercise limitation in patients with heart failure and normal ejection fraction. J Am Coll Cardiol 2010;56:85563.

11. Ommen SR, Nishimura RA, Appleton CP, Miller FA, Oh JK, Redfield MM, Tajik AJ. Clinical utility od Doppler echocardiography and tissue Doppler imaging in the estimation of left ventricular filling pressures. Circulation 2000;102:1788-94.

12. Nagueh SF, Mikati I, Kopelen HA, Middleton KJ, Quinones MA Zoghbi WA. Doppler estimation of left ventricular filling pressure in sinus tachycardia. A new application of tissue Doppler imaging. Circulation 1998;98:1644-50.

13. Dokainish H, Nguyen JS, Sengupta R, Pillai M, Alam M, Bobek J, and Lakkis N. Do additional echocardiographic variables increase the accuracy of $E / e^{\prime}$ for predicting left ventricular filling pressure in normal ejection fraction? An echocardiographic and invasive hemodynamic study. J Am Soc Echocardiogr 2010;23:156-61.

14. Dokainish H, Zoghbi WA, Lakkis NM, Al-Bakshy F, Dhir M, Quinones MA, Nagueh SF. Optimal noninvasive assessment of left ventricular filling pressures. Circulation 2004;109:2432-39.

15. Rivas-Gotz C, Manolios M, Thohan V, and Nagueh SF. Impact of left ventricular ejection fraction on estimation of left ventricular filling pressures using tissue Doppler and flow propagation velocity. Am J Cardiol 2003;91:780-4.

16. Dalsgaard M, Kjaergaard J, Pecini R, Iversen KK, Kober L, Moller JE, Grande $\mathrm{P}$, Clemmensen $\mathrm{P}$, and Hassager Ch. Left ventricular filling pressure estimation at rest and during exercise in patients with severe aortic valve stenosis: comparison of echocardiographic and invasive measurements. J Am Soc Echocardiogr 2009;22:343-9. 